\title{
Künstliche Intelligenz, Deep Learning \& Co.
}

Die Größe eines Wortes stellt die relative Häufigkeit in den Beiträgen des Heft-Schwerpunktes dar.

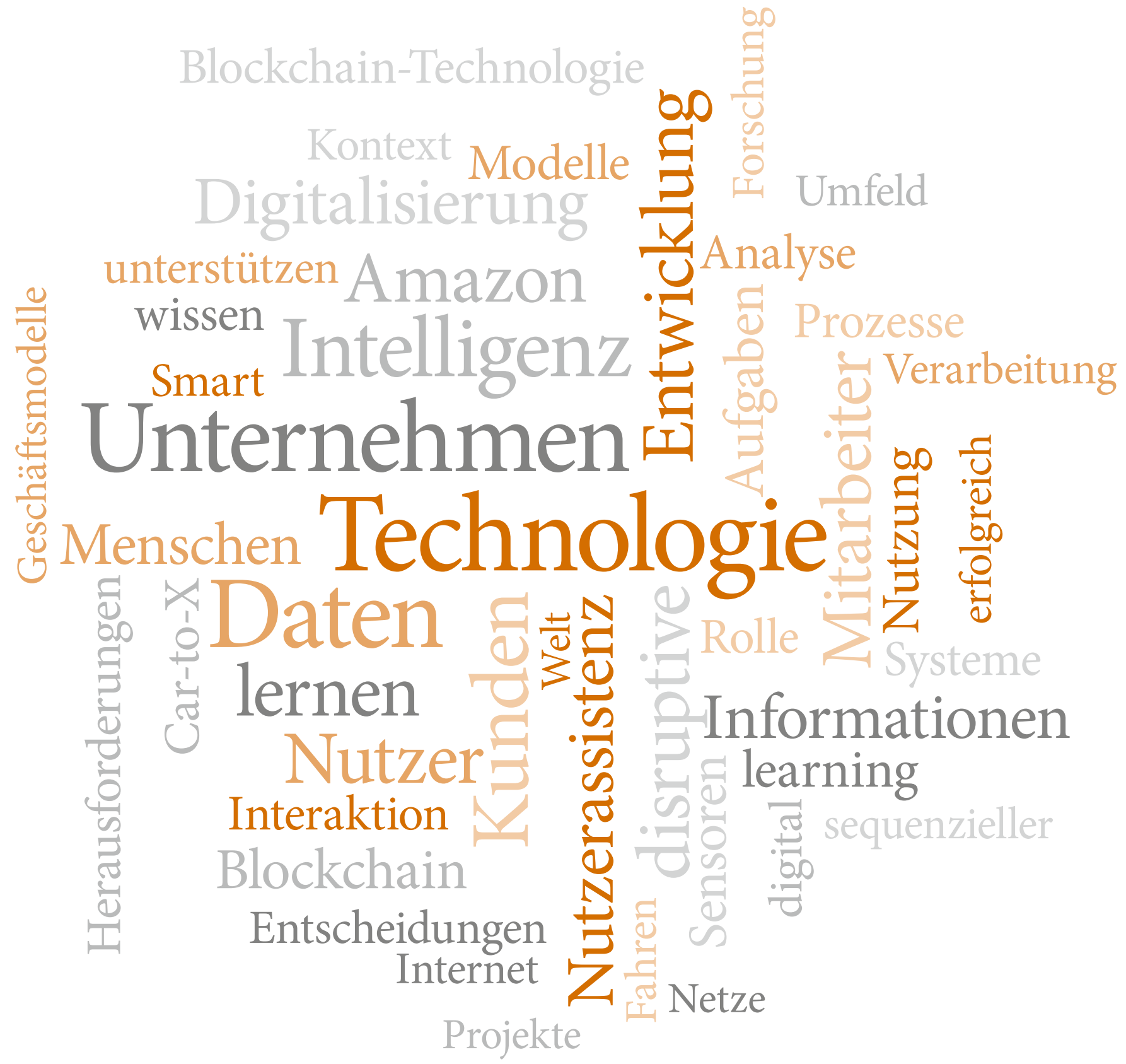

